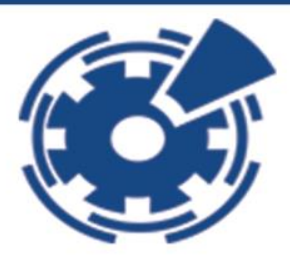

26-28 July, 2019 London, United Kingdom

\title{
Monitoring of Thermal Effect of Redox Flow Battery by the Infrared Thermal Image Technology
}

\author{
Chi-Ping Li ${ }^{1}$, Mei-Ling Chen², Chen-Chen Tseng ${ }^{1}$, Shu-Ling Huang,** \\ ${ }^{I}$ Department of Chemical Engineering, National United University, Miaoli 360, Taiwan \\ ${ }^{2}$ Department of Electrical Engineering, National United University, Miaoli 360, Taiwan, \\ *Corresponding author: Shu-Ling Huang, Department of \\ Chemical Engineering, National United University,
}

\begin{abstract}
RFB (redox flow battery) generate heat when consume the electric power in working state, and that will transfer into a thermal form emitted from the normal or abnormal state; therefore, it is important to control the thermal effect for battery's performance and safety improvement. Specifically, RFB will bring big thermal effect when the cell charged or discharged by the higher electric current. Due to the different battery's components and stack designs, the problems of RFB system identified by looking at the uneven heat distribution, the reduction of the battery's performance and life cycle. Therefore, it is important to understand the battery's thermal effect in high-rate discharge or its thermal effect in overcharge cases for the state of battery's health ( $\mathrm{SOH})$. Infrared thermal imager (IRTI) is a non-contact measurement, and that composed by the lens and computer analysis system. IRTI can detect a certain area of the temperature change, whereby the analysis can effectively identify the real hot spots, and make further improvements for RFB system's design. In this study, we developed a single cell to design the battery's stack of FB system and investigate battery's performance changes. Infrared thermal imaging technology applied to analyze and evaluate the thermal effect of battery's stack effectively. The high-resolution images with the function of the temperature profile data used to evaluate the components of the stacks or the key materials for RFB performance, and explore the possibility of its development.
\end{abstract}

Keywords: hot spots; infrared thermal imager; life cycle; overcharge; redox flow battery

\section{Introduction}

Redox Flow Battery (RFB) is a reversible energy storage system that uses the electrochemical reactions to convert electrical energy into chemical energy. The power and capacity of the RFB designed to be a megawatt or higher energy storage grid mainly base on the battery size, electrolyte volume, concentration, and battery stack [1]. Among them, Vanadium Redox Flow Battery (VRFB) is the most promising electrochemical energy storage system [2-8]. Temperature is one of 


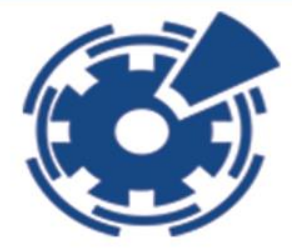

the main factors affecting battery performance and lifetime. For example, Li-ion batteries (LIBS) are prone to excessive heat, and there is a risk of thermal runaway, fire, explosion, etc. $[9,10]$. Therefore, some investigators use infrared thermal imager (IRTI) to detect and analyze thermal effect of lithium batteries because IRTI has the advantages of non-destructive detection, noncontact measurement, rapid temperature measurement and high sensitivity. In order to prevent premature performance degradation, the researchers used the (IRTI) to observe the effects of thermal runaway because short circuit [11] and fast charge and discharge. Although dynamic thermal simulation models of VRFB system based on the conservation of mass and energy have studied by some researchers [12-14]. However, there is no literature utilize the IRTI technology to explore the thermal effect of RFB system in the charge and discharge cycle.

In our study, we used the IRTI to monitor the thermal effects in the charge-discharge process for RFB system. By the monitoring of IRTI, we evaluated the thermal effect and the performance of key materials of a semi-V/I RFB in the charge/discharge cycles.

\section{Experimental}

We designed a single cell of all-VRFB and semi-V/I RFB, which comprised a pair of electrodes, electrolytes, separation membrane, a pair of flow channels, and a pair of current collectors, as shown in Fig. 1. The effective area of the electrode was $5 \times 5 \mathrm{~cm}^{2}$. The electrolyte solutions cyclically pumped into the corresponding half-cell. Next, a charge-discharge test was conducted using a battery cycler system WBCS3000 (Top Trans, Korea) and CT2001C-10 V/2A (Wuhan Land Co., China). In the all-VRFB system, the supporting electrolyte is $2.0 \mathrm{M} \mathrm{H}_{2} \mathrm{SO}_{4}, 1.0$ $\mathrm{M} \mathrm{V}^{2+} / \mathrm{V}^{3+}$ couple is as a negative electrolyte and $1.0 \mathrm{M} \mathrm{V}^{4+} / \mathrm{V}^{5+} / 2.0 \mathrm{M} \mathrm{H}_{2} \mathrm{SO}_{4}$ is as a positive electrolyte, which were circulated between the electrolytic half cells and a storage tank at $25 \mathrm{~mL}$ of electrolyte solutions. In semi-V/I RFB system, the components are similar all-VRFB, the only different is the original negative electrolyte $\left(\mathrm{V}^{3+} / \mathrm{V}^{2+}\right)[15]$ is replaced by the $\left(\mathrm{I}^{-} / \mathrm{I}_{2}\right) /$ vitamin $\mathrm{C}$. Thermal effect of RFB was monitored by the IRTI in charge-discharge cycle under different electrolyte, channel model and charge-discharge parameters. The parameter conditions for charge and discharge test included current density and flowing velocity. The IRTI was using a G100EXD model (Nippon Avionics Co., Ltd., Japan), which has a temperature range of $-40{ }^{\circ} \mathrm{C}$ to $1500^{\circ} \mathrm{C}$, and the limiting resolution of temperature is $0.04^{\circ} \mathrm{C}$. 


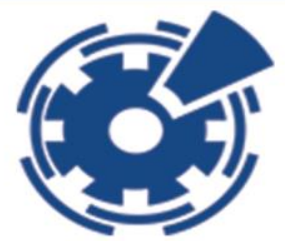

26-28 July, 2019 London, United Kingdom

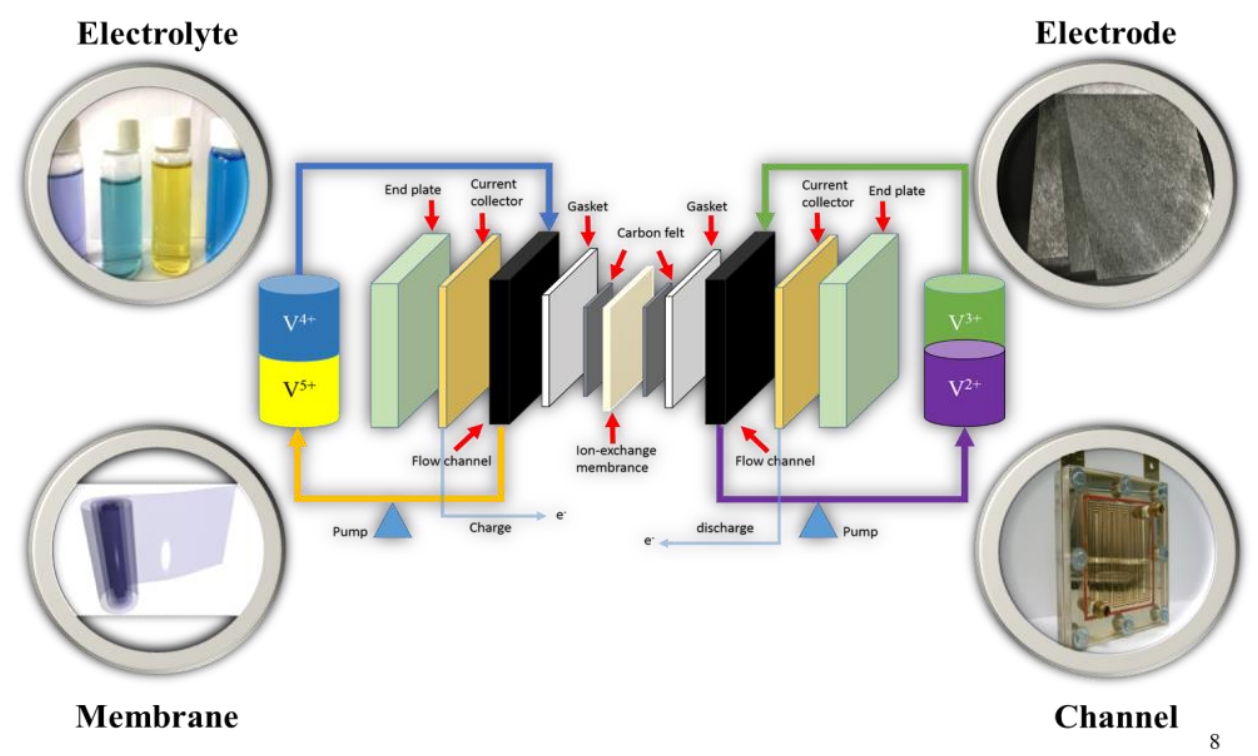

Fig. 1. Component schematic of an all-VRFB

\section{Results and discussion}

\subsection{Thermal effect of all-V RFB and semi-V/I RFB systems}

Fig. 2 shows that the performances of the all-V RFB and semi-V/I RFB systems without modified key materials for charge-discharge test at 10 hours; Nafion 117 is as the separation membrane and carbon paper as electrodes with a parallel type flow channel. The cell's performances, coulombic efficiency (CE\%), voltage efficiency (VE\%) and the energy efficiency (EE \%), were listed in Table 1. All-V RFB system presents a higher EE \% (62\%) than semi-V/I RFB system (57\%), because that semi-V/I RFB showed a low VE\% (61\%); however, it showed a higher CE\% (93\%) than of that all-V RFB system (79\%).

The standard formation enthalpy of all-VRFB electrolyte knows from the literature [15], the standard enthalpy change $\left(\Delta \mathrm{H}_{\mathrm{r}}^{\circ}\right)$ of all-VRFB during charging is $155.6 \mathrm{~kJ} \mathrm{~mol}^{-1}$, which is an endothermic reaction and an exothermic reaction during discharge. It can be seen from literature $[16,17]$ that the standard enthalpy changes of semi-V/I RFB during charging is $66.33 \mathrm{~kJ} \mathrm{~mol}^{-1}$ and the exothermic reaction occurred in discharge. All-VRFB has a greater reaction heat than semiV/I RFB, so showing a large temperature amplitude change after 3.5 hours' charge and discharge, as shown in Fig. 3.

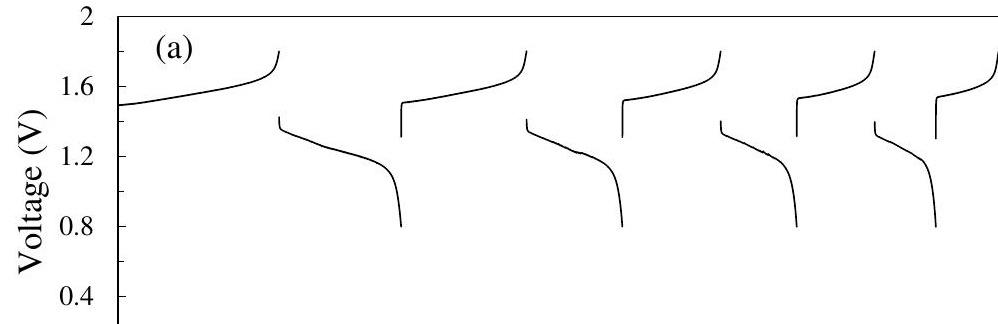




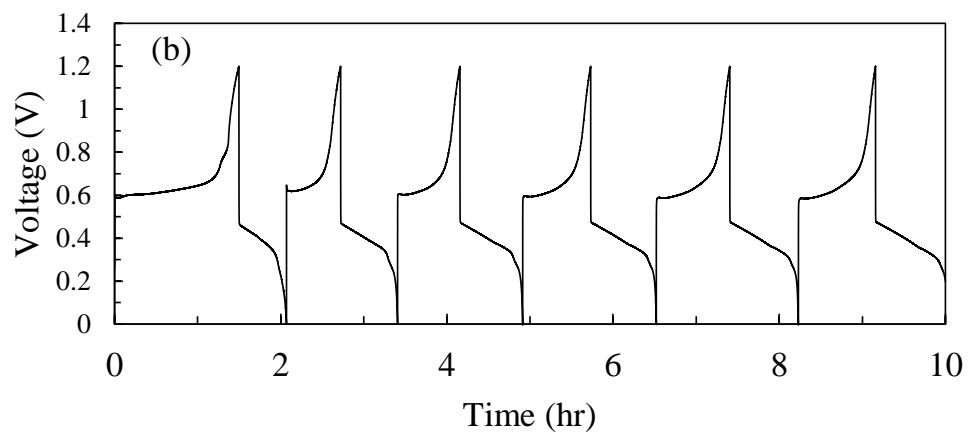

Fig. 2. Charge-discharge diagrams of (a) all-VRFB and (b) a semi-V/I RFB without modified key components.

Table 1 Charge-discharge performances of all-VRFB and semi--V/I RFB systems without modified key components

\begin{tabular}{lccc}
\hline \multicolumn{1}{c}{ RFB } & CE $(\%)$ & VE $(\%)$ & EE $(\%)$ \\
\hline all-VRFB & 79 & 79 & 62 \\
semi-V/I RFB & 93 & 61 & 57 \\
\hline
\end{tabular}

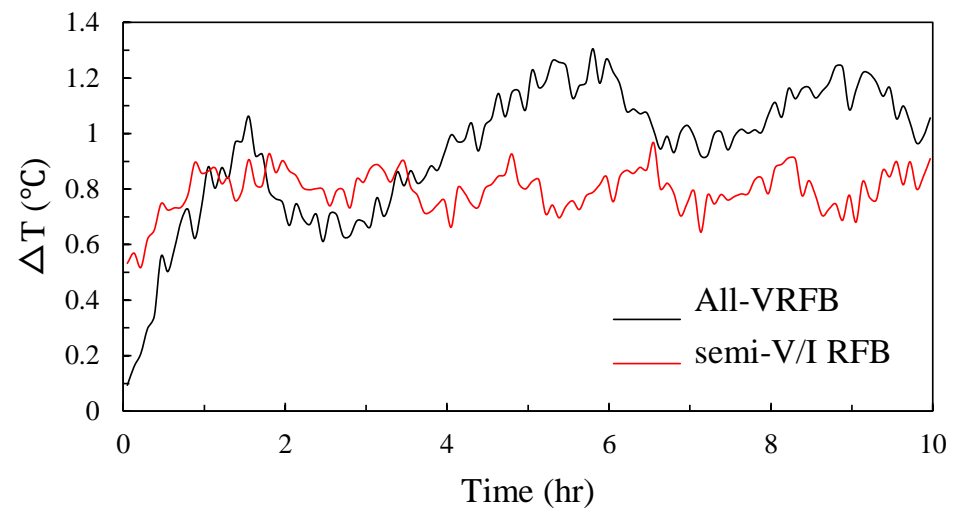

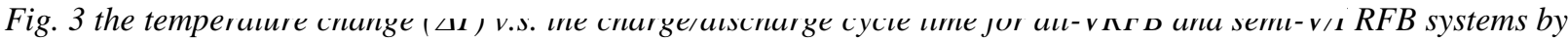
monitoring of the IRTI.

Therefore, the semi-V/I RFB can not only reduce the amount of vanadium salt and cost down, but also can decrease the thermal effect. The key materials, such as electrodes, separation membrane, and flow channel were further improved, and the overall efficiency will be enhanced. 


\subsection{Thermal effect of charge-discharge parameters for semi-V/I RFB}

Fig. 4 shows that the temperature change $(\Delta \mathrm{T})$ v.s. cycle time for semi-V/I RFB system with different flow rate for charge-discharge test. After one hour, at a flow rate of $40 \mathrm{rpm}$, it shows a large temperature amplitude change, $\Delta \mathrm{T}>1.2^{\circ} \mathrm{C}$ (on discharging), comparing to 70rpm and 100 $\mathrm{rpm}$. Simultaneously, the VE\% (51\%) was lowest than others operating rates, as summarized in Table 2, indicating that the residence time was too long on the electrode's surface, so the concentration polarization is worse. The thermal effect was small $\left(\Delta \mathrm{T}<1.0^{\circ} \mathrm{C}\right)$ at $70 \mathrm{rpm}$ and 100 rpm, but the VE\% (55\%) of 100rpm was lower than 70rpm (61\%), meaning that the electrolytes flowing through the electrodes surface is too fast and the oxidation-reduction reaction does incomplete. Therefore, the optimum flow rate was $70 \mathrm{rpm}$ for a semi-V/I RFB system.

With the increasing of current density, the CE\% can reach more than 90\%, but the VE\% shows a downward trend, as present in Table 2. Using a large current density to charge, the concentration change is remarkable, causing an overvoltage phenomenon of concentration polarization, which lowers the efficiency. When the current density is more large $\left(60 \mathrm{~mA} / \mathrm{cm}^{2}\right)$, the thermal released by the ohmic resistor will be greatly increased, and VE\% rapid dropping, so that the $\Delta \mathrm{T}$ is significantly greater than $20 \mathrm{~mA} / \mathrm{cm}^{2}$ and $40 \mathrm{~mA} / \mathrm{cm}^{2}$, as shown in Fig. 5 .

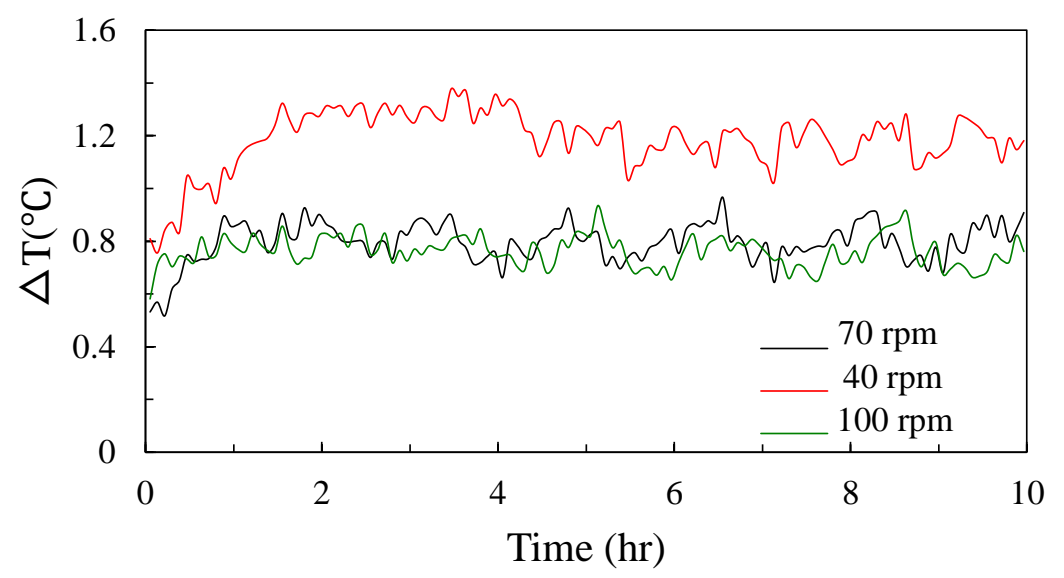

Fig. 4 the temperature change ( $\left.\Delta^{\prime} \mathbf{I}^{\prime}\right)$ v.s. the charge/discharge cycle time for semi-V/I RFB system with different flow rate by monitoring of the IRTI.

Table 2 Charge-discharge performance of the semi-V/I RFB system with various charge-discharge parameters

\begin{tabular}{ccccc}
\hline $\begin{array}{c}\text { charge-discharge } \\
\text { parameters }\end{array}$ & Types & CE $(\%)$ & VE $(\%)$ & EE $(\%)$ \\
\hline Flow rate & $40 \mathrm{rpm}$ & 85 & 51 & 43 \\
& $70 \mathrm{rpm}$ & 93 & 61 & 57 \\
& $100 \mathrm{rpm}$ & 91 & 55 & 50 \\
Current density & $20 \mathrm{~mA} / \mathrm{cm}^{2}$ & 93 & 60 & 56 \\
\hline
\end{tabular}




\begin{tabular}{llll}
\hline $40 \mathrm{~mA} / \mathrm{cm}^{2}$ & 93 & 61 & 57 \\
$60 \mathrm{~mA} / \mathrm{cm}^{2}$ & 91 & 17 & 16 \\
\hline
\end{tabular}

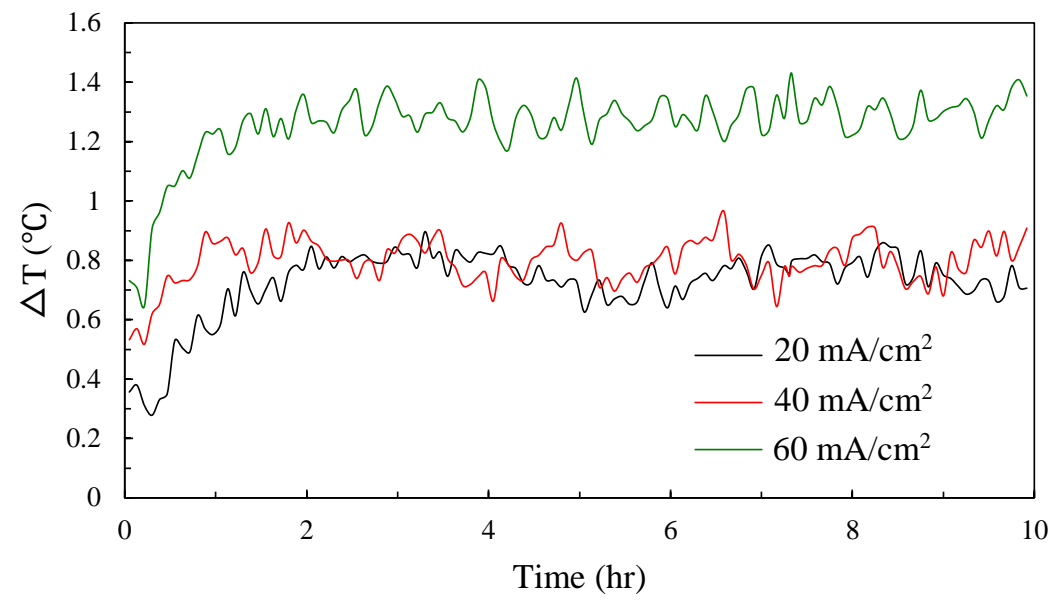

$F$

current density by monitoring of the IRTI.

ystem with different

\subsection{The charge-discharge test of a semi-V/I RFB}

\subsubsection{Thermal effect of key materials}

Fig. 6(a) shows the thermal effect analysis of the Nafion 117 and $\mathrm{HS}-\mathrm{SO}_{3} \mathrm{H}$ films applied to the semi-V/I RFB system for 10 hours' charge/discharge test. The results found that the $\Delta \mathrm{T}$ between the two is small. The carbon paper electrode $(\mathrm{C})$ and $\mathrm{C} / \mathrm{TiO}_{2} / \mathrm{Pd}$ composite electrode used to the semi-V/I RFB system for 10 hours' charge-discharge test. The result showed that the driving voltage of $\mathrm{C} / \mathrm{TiO}_{2} / \mathrm{Pd}$ electrode was larger than $\mathrm{C}$ electrode, causing a large activation heat, so that the $\Delta \mathrm{T}$ is clearer before 5 hours. However, after 5 hours, the subsequent reaction proceeds, the $\Delta \mathrm{T}$ approaches agreement with $\mathrm{C}$ electrode, as shown in Fig. 6 (b). After 10 hours of charge and discharge cycle, the serpentine channel can still maintain a high coulombic efficiency (CE) of 93\%, as listed in Table 3. Fig. 6 (c) shows the thermal effect analysis of the parallel and the serpentine models. The results present that the $\Delta \mathrm{T}$ of the serpentine channel is greater than that of the parallel channel. From the result speculated that the electrolyte undergoes an oxidationreduction reaction on the electrode surface in a meandering flow path, which can increase the connecting area, thus the large amount of the reaction heat is generated.

\subsubsection{The performance of a semi-V/I RFB}

Fig. 7 shows charge-discharge diagrams of a semi-V/I RFB system with modified key materials. The $1.0 \mathrm{M} \mathrm{VOSO}_{4} / 2.0 \mathrm{M} \mathrm{H}_{2} \mathrm{SO}_{4}$ was as the positive electrolyte, iodine-vitamin $\mathrm{C}$ solutions as the negative electrolyte, and $\mathrm{C}$ electrode as the positive electrode, $\mathrm{HS}-\mathrm{SO}_{3} \mathrm{H}$ as the separation membrane, $\mathrm{C}-\mathrm{TiO}_{2}-\mathrm{Pd}$ as the negative electrode with a serpentine-type flow channel at a current density of $40 \mathrm{~mA} \mathrm{~cm}{ }^{-2}$. An $\mathrm{HS}-\mathrm{SO}_{3} \mathrm{H}$ modified membrane enhanced the $\mathrm{CE}$ value 


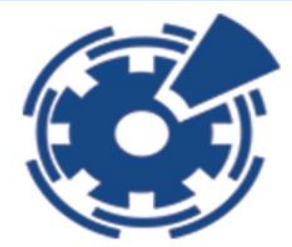

26-28 July, 2019 London, United Kingdom

from $93 \%$ to $96 \%$, implying that the $\mathrm{HS}-\mathrm{SO}_{3} \mathrm{H}$ groups prevent the crossover pollution of ions and thereby promote the transfer of $\mathrm{H}^{+}$protons. With $\mathrm{C}-\mathrm{TiO}_{2}-\mathrm{Pd}$ as a negative electrode with serpentine flow channel for semi-V/I RFB system, considerable increase of the system's CE was from $93 \%$ to $96 \%$, the VE\% was enhanced from $61 \%$ to $84 \%$, as shown in Table 4 . The key materials were modified through various methods to effectively improve the performance of a semi-V/I RFB system, the whole EE\% was improved from 57\% to $81 \%$.

Table 3 Charge-discharge performance of the semi-V/I RFB system with various key components

\begin{tabular}{ccccc}
\hline Key materials & Types & $\mathrm{CE}(\%)$ & $\mathrm{VE}(\%)$ & $\mathrm{EE}(\%)$ \\
\hline Separation membrane* & $\mathrm{N}-117$ & 93 & 61 & 57 \\
& $\mathrm{HS}^{-S O}{ }_{3} \mathrm{H}$ & 94 & 60 & 57 \\
Negative electrode* & $\mathrm{C}$ & 94 & 60 & 57 \\
& $\mathrm{C}^{-} \mathrm{TiO}_{2}-\mathrm{Pd}$ & 93 & 81 & 75 \\
Flow channel & serpentine & 96 & 84 & 81 \\
& parallel & 93 & 61 & 57 \\
\hline
\end{tabular}

* Using parallel channel
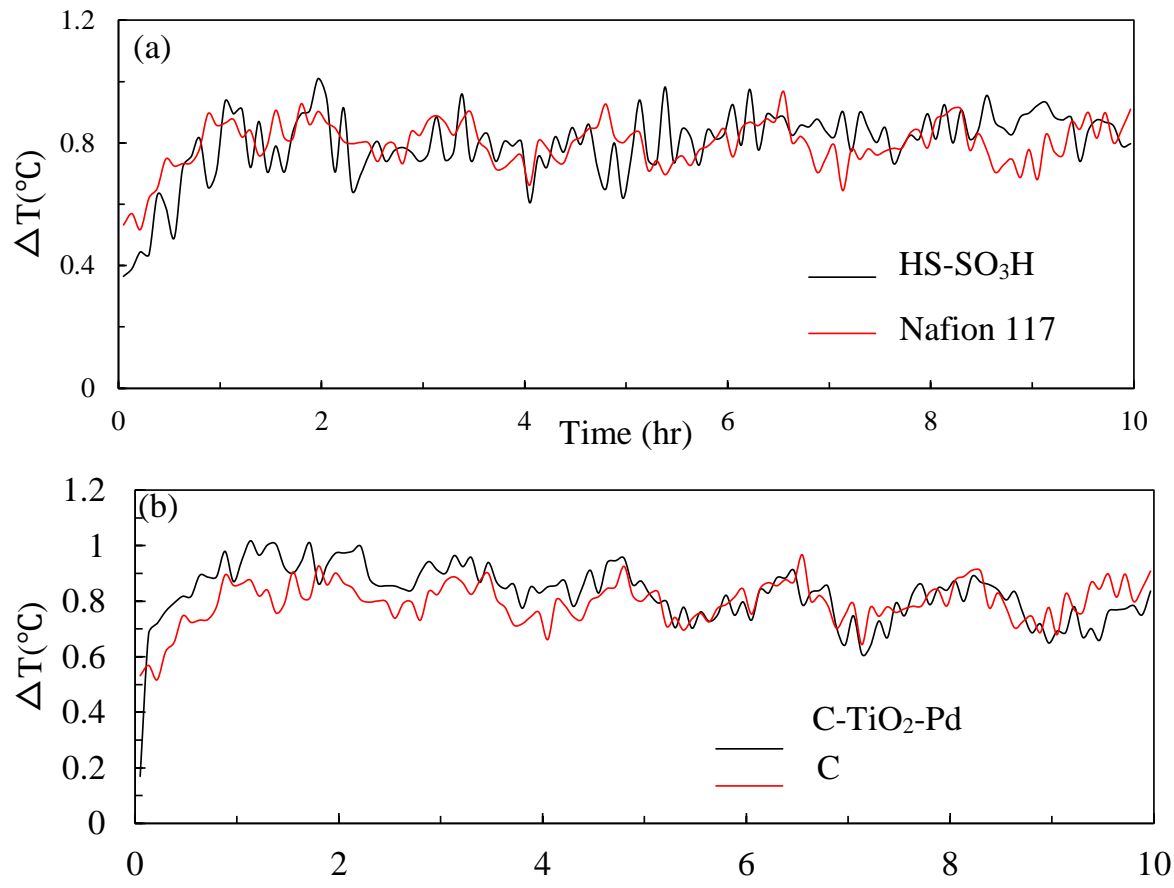

(c)

Time (hr)

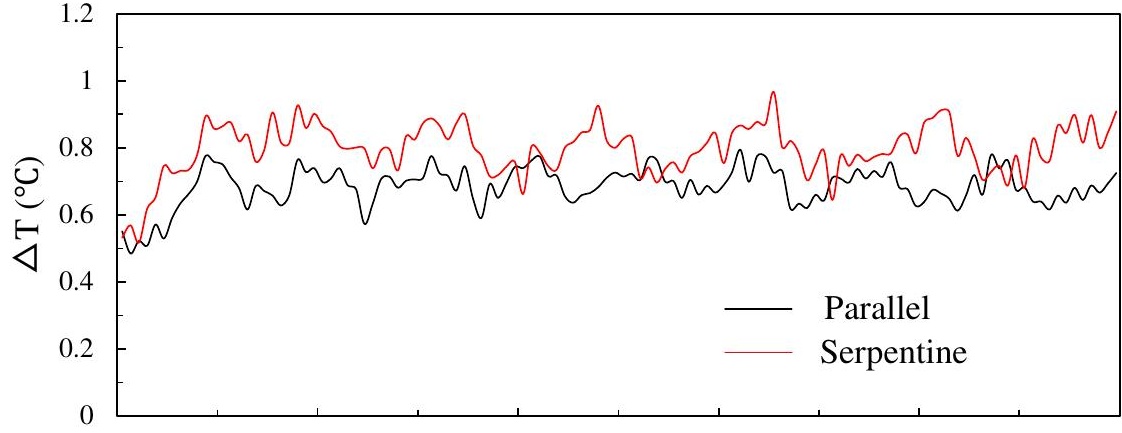


Fig. 6 shows the temperature change $(\Delta T)$ v.s. the charge/discharge cycle time for semi-V/I RFB system with different key materials: (a) separation membrane, (b) electrodes and (c) flow channels.

Table 4 Charge-discharge performance of all-VRFB and semi-V/I RFB systems without modified key components

\begin{tabular}{lccc}
\hline \multicolumn{1}{c}{ RFB } & CE (\%) & VE(\%) & EE(\%) \\
\hline semi-V/I RFB* & 93 & 61 & 57 \\
semi-V/I RFB & 96 & 84 & 81 \\
\hline
\end{tabular}

* Without modified key materials

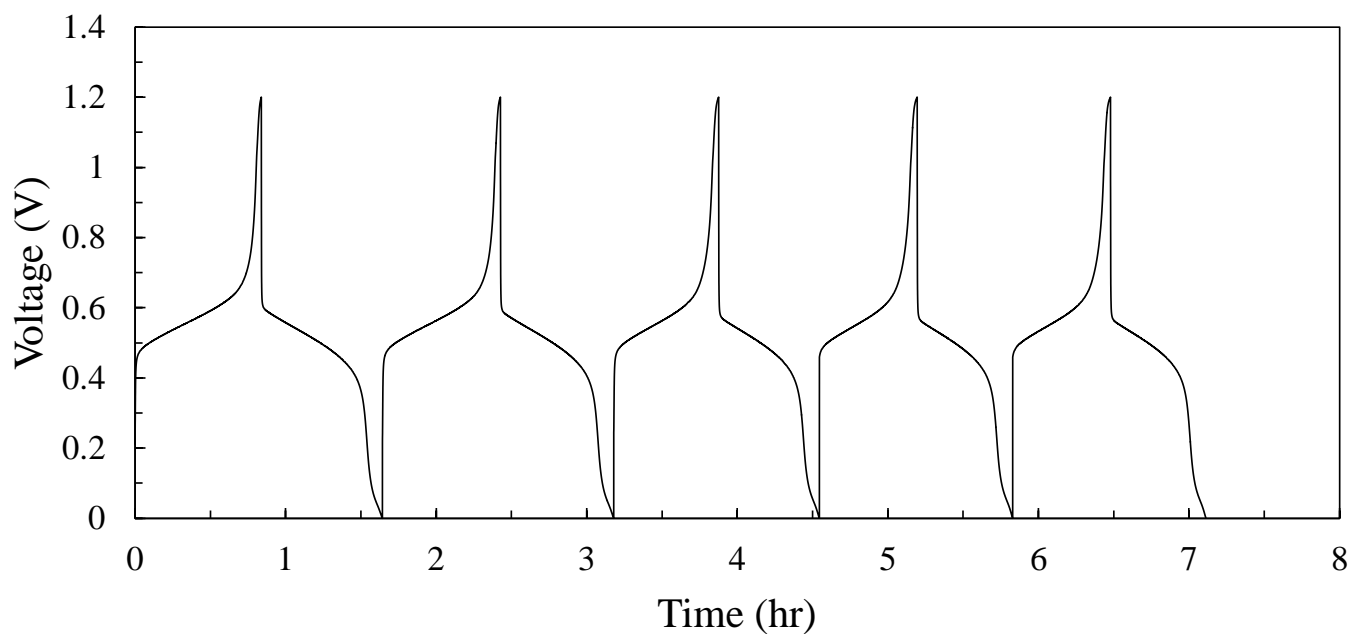

Fig. 7. Charge-discharge diagrams of a semi-V/I RFB system with modified key materials. 


\section{Conclusions}

Through experimental design and combined with the monitoring of infrared thermal imager (IRTI) thermal analysis at charge/discharge test can efficiently evaluate the performance of key materials for the development of RFB system. From the thermal effect analysis results, showed that the parameters (flow rate and current density) of charge/discharge test affect the thermal effect of a semi-V/I RFB system. High current density cause a phenomenon of concentration overvoltage and the thermal release is more serious. The optimum flow rate was $70 \mathrm{rpm}$ and obtained the highest energy efficiency. When the flow rate is too slow, causing the concentration gradient and a higher ohmic resistance heat release, which reduce the efficiency. The results proved that through combining our experiments with the IRTI, the influence of key material on the performance of a semi-V/I RFB system was understood effectively, the battery's temperature distributed model was established and show a potential for the development of a new RFB in the future.

\section{Acknowledgments}

The authors are grateful for the financial support by the Ministry of Science and

Technology, Taiwan (MOST 107-2635-E-239-001).

\section{References}

1. Lawrence H.Thaller, "Electrically rechargeable redox flow cells", 1974.

2. W. Wang, Q. Luo, B. Li, X. Wei, L. Li, Z. Yang, "Recent progress in redox flow battery research and development", Advanced Functional Materials, 23 (2013), pp. 970-986

3. Y.K. Zeng, T.S. Zhao, L. An, X.L. Zhou, L. Wei, "A comparative study of all-vanadium and iron-chromium redox flow batteries for large-scale energy storage", Journal of Power Sources, 300 (2015), pp. 438-443

4. F. Rahman, M. Skyllas-Kazacos, "Vanadium redox battery: Positive half-cell electrolyte studies", Journal of Power Sources, 189 (2009), pp. 1212-1219

5. M. Skyllas-Kazacos, J.F. McCann, "Advances in Batteries for Medium and Large-Scale Energy Storage- Chapter 10 - Vanadium redox flow batteries (VRBs) for medium- and large-scale energy storage", A volume in Woodhead Publishing Series in Energy(2015), pp. 329-386

6. T.M. Lim, M. Ulaganathan, Q. Yan, "Advances in Batteries for Medium and Large-Scale Energy Storage- Chapter 14 - Advances in membrane and stack design of redox flow batteries (RFBs) for medium- and large-scale energy storage", A volume in Woodhead Publishing Series in Energy(2015), pp. 477-507 
7. M. Skyllas-Kazacos, C. Menictas, "Electricity Transmission, Distribution and Storage Systems- 12 - Redox flow batteries for medium- to large-scale energy storage", A volume in Woodhead Publishing Series in Energy(2013), pp. 398-441

8. A. Lucas, S. Chondrogiannis, "Smart grid energy storage controller for frequency regulation and peak shaving, using a vanadium redox flow battery", Journal of Power Sources, 80 (2016), pp. 26-36

9. S. Eckroad "Vanadium redox fl ow batteries: An in-depth analysis", Technical Report EPRI-1014836, Electric Power Research Institute, Palo Alto, CA (2007)

10. G. Yang, J. Zhang, X. Lu, D. Choi, "Electrochemical Energy Storage for Green”, Pacific Northwest National Laboratory, Richland, Washington 99352, United States

11. H. Maleki, J.N. Howard, "Internal short circuit in Li-ion cells", J. Power Sources, 191 (2009), pp. 568-574

12. B. Xiong, J. Zhao, K.J. Tseng, M. Skyllas-Kazacos, T.M. Lim, Y.Zhang, "Thermal hydraulic behavior and efficiency analysis of an all-vanadium redox flow battery", Journal of Power Sources, 242 (2013), pp. 314-324

13. Z.B. Wei, J.Y. Zhao, B.Y. Xiong, "Dynamic electro-thermal modeling of all-vanadium redox flow battery with forced cooling strategies", Journal of Applied Energy, 135 (2014), pp. $1-10$

14. Q. Zheng, H. Zhang, F. Xing, X. Ma, X. Li, G. Ning, "A three-dimensional model for thermal analysis in a vanadium flow battery", Journal of Applied Energy, 113 (2014), pp. $1675-1685$

15. Q. Zheng, H. Zhang, F. Xing, X. Ma, X. Li, G. Ning, "A three-dimensional model for thermal analysis in a vanadium flow battery", Journal of Applied Energy, 113 (2014), pp. 16751685

16. A.J. Bard, R. Parsons, J. Jordan, “Standard Potentials in Aqueous Solution”, prepared under the auspices of IUPAC, CRC Press

17 T. S. Chen, S. L. Huang, M. L. Chen, T. J. Tsai, Y. S. Lin, "Improving Electrochemical Activity in a Semi-V-I Redox Flow Battery by Using a C-TiO2-Pd Composite Electrode", Journal of Nanomaterials (2019), https://doi.org/10.1155/2019/7460856 